\title{
든oughborough University
}

The Taylor Rule and Dynamic Stability in a Small Macroeconomic Model

\section{David Chappell and Paul Turner}

\section{Department of Economics}

\author{
University of Sheffield
}

March 2002

Revised April 2003

\begin{tabular}{|c|}
\hline This article has \\
been submitted to \\
Loughborough \\
University's \\
Institutional \\
Repository by the \\
author. \\
\hline
\end{tabular}

Correspondence Address:

Dr Paul Turner

Department of Economics

University of Sheffield

9 Mappin Street

Sheffield

S1 4DT

Tel: (0114) 2223404

E-Mail: p.turner@sheffield.ac.uk 


\begin{abstract}
In this paper we embed the Taylor interest rate rule in a simple macroeconomic model with Calvo contracts. We contrast this with the case in which the interest rate is determined by the conventional LM curve along with a fixed value for the monetary aggregate. We derive conditions under which the adjustment of the economy is characterised by a unique saddle-path and show that the conditions required for this to be the case are more stringent when the authorities adopt the Taylor rule. In both cases the possible failure of the saddle-path condition arises when there are debtdeflation effects in the IS curve. If interest rates are set according to the Taylor rule, then debt-deflation is always enough to cause the failure of the saddle-path condition. However, when interest rates are determined by the LM curve then it is possible that the real balance effect from the LM curve may offset the debt-deflation effect and produce a saddle-path.
\end{abstract}

Keywords: Inflation, Taylor Rule, debt-deflation.

JEL Codes: E4, E5

Acknowledgements: Thanks are due to comments from Sean Holly and two anonymous referees. However, any errors remain our responsibility. 


\section{Introduction}

During the last decade there has been a general movement towards the use of explicit inflation targets by independent Central Banks as the monetary policy framework in developed economies. By recent historical standards this has proved to be a remarkable success. Inflation rates within the industrialised world have stabilised at low levels that would have been regarded as hopelessly over optimistic in the 1970s and 1980s. Moreover this success has not been bought at the expense of the performance of the real economy since growth rates have also proved robust even in the face of numerous external shocks. The reason for the success of this type of monetary arrangement can be argued to be the combination of the delegation of authority to more or less independent Central Banks coupled with an easily understood objective. These factors seem to have negated the dynamic inconsistency problems which plagued earlier systems.

The success of the new monetary arrangements has not however, come without associated problems. Firstly, an inflation target is a statement about the objective of monetary policy rather than a policy in itself. There is therefore the need for a widely understood operational rule to complement the target. Taylor (1993) has set out one possible such rule which links the interest rate to deviations of inflation and output from target values chosen by the monetary authorities. An alternative is provided by Svensson (1997) who links the current interest rate to a forecast of future inflation. In practice these rules produce similar outcomes since expectations of future inflation are often conditioned on current inflation and the current output gap.

Under Taylor's rule the economy behaves rather like one in which the authorities set a fixed money growth rate and in which the short-run demand for money function is stable. The interest rate rises during the upswing of the cycle, as output rises and inflation accelerates, and falls during the downswing. There is evidence that this describes actual policy well. For example, Taylor, in his original paper, demonstrates that this simple formulation captures US interest rate policy in the 1980s accurately. 
For the UK, Goodhart (1999) has uses the Taylor rule to describe recent UK monetary policy. Moreover, Bean (1998) has shown that a Taylor type rule for the UK can be derived from an optimising framework and is consistent with a small empirical model while Batini (1999) has made use of a Taylor rule to assess the properties of UK monetary policy within a small calibrated model. There is also evidence that the forward looking Phillips curve specification fits the data well. Recent papers by Gali and Gertler (1999) for the USA and Gali, Gertler and Lopez-Salido (2001) for Europe have found a significant forward looking element in inflationary expectations.

One problem associated with the success of this new monetary policy has been the reemergence of debt deflation as a problem in a number of economies. Low inflation rates have meant that countries with high levels of personal sector debt can no longer rely on the relatively swift erosion of the real value of debt through inflation. This has been a particular problem in Japan and the other Asian economies where a collapse in equity markets has reduced the value of assets significantly below their expected values. The result has been an increase in the rate of business failure in which the low or negative rate of inflation has acted to exacerbate the problem in the way first analysed by Fisher (1933) for the Great Depression. During the high inflation era of the 1970s and 1980s the debt-deflation or Fisher effect was regarded as a theoretical curiosity and largely ignored except for the notable contribution of Tobin (1980). More recently, King (1993) has interpreted the idea of debt-deflation as a shock to endowments in a real business cycle model and Wolfson (1996) has interpreted the events following the 1987 stock market crash in terms of the debt-deflation hypothesis. Wolfson's conclusion was that the fact that in 1987 most developed economies were on the upswing of the business cycle reduced the impact of debtdeflation. The current state of the world economy is however, rather less favourable and this raises the possibility that the problem of debt-deflation may spread.

In this paper we examine the interaction of debt-deflation and the use of a simple monetary policy rule. First, we incorporate an explicit Taylor rule into a small macroeconomic model in order to examine the implications for its dynamic properties. Second, we allow for the possibility of debt-deflation by allowing the short 
run response of aggregate demand to a fall in prices to be negative. In contrast with much of the recent work on Taylor rules which has focused on numerical simulations, we derive the basic theoretical properties of the model analytically. Our results indicate that, in a model with rational expectations, the adoption of a Taylor rule is more likely to lead to instability. Moreover, this instability is linked to the existence of the debt-deflation effect in the IS curve. These results are demonstrated using a continuous time framework based on Calvo’s (1983) model of price setting behaviour.

\section{Dynamics of Prices and Inflation}

The basis of our analysis is Calvo's model of prices. In this model contracts are assumed to have random duration. The probability that a contract will last a further $h$ time periods is given by the function $\delta e^{-\delta h}, \delta>0$. A firm setting its current contract price must therefore take into account the expected price of its rivals and the state of excess demand during the period in which the contract may be in force. Current contract prices are therefore a forward looking weighted average of future expected aggregate price levels and excess demand, weighted by the probability that the price currently being set will still be in force at each future date. Since this is a perfect foresight model we neglect the distinction between expected and actual values. The contract price $\psi$ is therefore determined by the following forward integral:

$$
\psi(t)=\delta \int_{t}^{\infty}\left[p_{s}+\beta y_{s}\right] e^{-\delta(s-t)} d s
$$

where $p_{s}$ and $y_{s}$ are the aggregate (log) price level and excess demand (deviation of (log) output from capacity) at date $s$ and $\beta>0$.

The current aggregate price level is a backward looking integral of contract prices set in previous periods as shown in equation (2): 


$$
p(t)=\delta \int_{-\infty}^{t} \psi_{S} e^{-\delta(t-s)} d s
$$

These equations imply the following pair of first order differential equations in $\psi$ and p:

$$
\begin{aligned}
& D \psi=\delta(\psi-p-\beta y) \\
& D p=\delta(\psi-p)
\end{aligned}
$$

where $D$ is the differential operator.

Some simple manipulation enables this system of first order equations to be written as a single second order equation in the aggregate price level:

$$
D^{2} p=-\delta^{2} \beta y
$$

It follows that the form of the excess demand function is of crucial importance in determining the dynamic behaviour of the model. What we require is an excess demand function which relates $y$ to $p$ and its derivatives. Let us begin by setting out a general reduced form model for excess demand:

$$
y=b_{0}+b_{1} D p+b_{2} p
$$

Equation (5) embodies the idea that there will be both price level and inflation effects on aggregate demand. The signs of $b_{1}$ and $b_{2}$ will depend on the short run model used to determine output and the rate of interest. We can combine (4) and (5) into a single second order differential equation which takes the form:

$$
D^{2} p+\delta^{2} \beta b_{1} D p+\delta^{2} \beta b_{2} p=-\delta^{2} \beta b_{0}
$$


Let $\pi=D p$ be the inflation rate. We can then write (6) as a pair of first order linear differential equations in the inflation rate and the price level as shown in

$$
\left[\begin{array}{c}
D \pi \\
D p
\end{array}\right]=\left[\begin{array}{cc}
-\delta^{2} \beta b_{1} & -\delta^{2} \beta b_{2} \\
1 & 0
\end{array}\right]\left[\begin{array}{l}
\pi \\
p
\end{array}\right]+\left[\begin{array}{c}
-\delta^{2} \beta b_{0} \\
0
\end{array}\right]
$$

Since $\Delta=\delta^{2} \beta b_{2}$ is the determinant, we can identify the condition for a saddle-path solution as $b_{2}<0^{\mathrm{i}}$. This condition indicates that the only policy rules which give rise to a unique saddle path solution are those which produce a reduced form with $b_{2}<0$. We demonstrate in section III that a necessary and sufficient condition for this to be the case is that there be a sufficiently large price level effect in the policy rule to outweigh any possible debt-deflation effect in the IS curve. In principle it is possible to design a whole range of rules with this property. The example we use is the case where the authorities fix the monetary aggregate and then allow the interest rate to be determined by the market. Howvever, another example of a policy rule which would meet this condition is if the monetary authorities use the interest rate to target the price level $\left(i_{t}=\gamma\left(p_{t}-\beta\right)\right.$ where $\gamma>0$ and $\beta c$ is the target price level).

\section{Implications of the Taylor Rule}

We have seen that the existence of a saddle path solution depends on the derivative of output with respect to the price level in the reduced form aggregate demand equation. In this section we show that the value of this coefficient depends on the nature of the monetary rule adopted by the Central Bank. In particular, we show that this coefficient is more likely to be positive, and therefore the economy is less likely to be characterised by a unique saddle path solution, when the authorities adopt a Taylor rule than when the interest rate is determined by the conventional LM curve. 
Consider the following pair of equations which are conventional IS and LM curves for a closed economy:

$$
\begin{aligned}
& y=\alpha_{0}+\alpha_{1}(i-\pi)+\alpha_{2}(m-p) \\
& m-p=\phi_{0}+\phi_{1} y+\phi_{2} i
\end{aligned}
$$

$i$ is the nominal interest rate and $m$ is the (log) money stock. We expect $\alpha_{1}<0, \phi_{1}>0$ and $\phi_{2}<0$. The sign of $\alpha_{2}$ is uncertain reflecting the possibility of a debt-deflation effect. The normal assumption is that a fall in the price level and a rise in real balances will produce an increase in aggregate demand i.e. $\alpha_{2}>0$. However, this assumes that the redistribution effects of changes in the price level can be ignored. Fisher and Tobin (op cit) have both argued that this may be invalid. When the price level falls then there is a redistribution of wealth from those agents with debt which are fixed in nominal terms to those with assets fixed in nominal terms. Since creditors are likely to have a lower propensity to spend than creditors, the effect of this may be to produce a net fall in aggregate demand. In terms of our model we accommodate this case by allowing for the possibility that $\alpha_{2}<0$.

From (8) we obtain the following reduced form equation for $y$ :

$$
y=-\frac{\alpha_{1} \phi_{2}}{\phi_{1} \alpha_{1}+\phi_{2}} \pi-\frac{\alpha_{1}+\alpha_{2} \phi_{2}}{\phi_{1} \alpha_{1}+\phi_{2}} p+\frac{\alpha_{1}+\alpha_{2} \phi_{2}}{\phi_{1} \alpha_{1}+\phi_{2}} m-\frac{\alpha_{0} \phi_{2}-\alpha_{1} \phi_{0}}{\phi_{1} \alpha_{1}+\phi_{2}}
$$

Combining (9) and (4) we can easily see that the system has a fixed point when inflation is constant and equal to the money growth rate.

The denominator $\phi_{1} \alpha_{1}+\phi_{2}$ in equation (9) is always negative. Therefore for the reduced form price level coefficient $b_{2}$ to be negative, we require $\alpha_{2}>-\frac{\alpha_{1}}{\phi_{2}}$. This is 
obviously satisfied if $\alpha_{2}>0$. However, even if there is a debt-deflation effect present such that $\alpha_{2}<0$ then it is still possible for there to be a unique saddle-path solution provided that the effect is sufficiently small to be offset by the conventional liquidity effect of lower prices on interest rates and investment. Note that the reduced form coefficient for inflation $b_{1}=-\frac{\alpha_{1} \phi_{2}}{\phi_{1} \alpha_{1}+\phi_{2}}$ is unambiguously positive. In the event that the saddle path condition is not met the solution is therefore either a globally stable node or a globally stable spiral ${ }^{\mathrm{ii}}$. However, the solution will not be unique by virtue of the fact that there is only one predetermined variable.

It is interesting to examine the dynamics of this model in response to a monetary surprise in the case where the saddle path condition is satisfied. Consider an economy in which money growth is zero and therefore both $p$ and $m$ are constant at $\left(p_{0}, m_{0}\right)$ in steady-state. Now assume that from an initial equilibrium position the authorities increase the stock of money from $m_{0}$ to $m_{1}$. In the new equilibrium the price level must increase from $p_{0}$ to $p_{1}$. In the short run the price level is sticky but inflation can jump immediately to put the economy on the saddle-path shown in Figure One. From this position the price level increases and the inflation rate declines towards the new equilibrium which is approached asymptotically. 


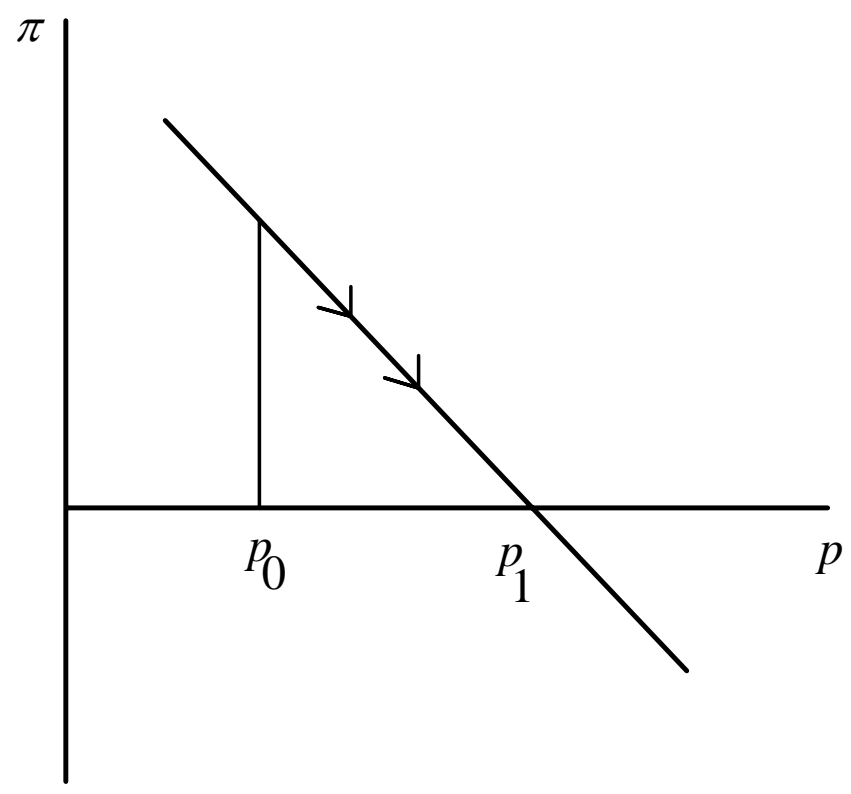

Figure One: Dynamics of inflation and price in response to a monetary disturbance

Next consider an economy in which we replace the LM curve with a Taylor rule. Interest rates are therefore determined by the following equation:

$$
i=\beta / \pi+\pi+w_{1}\left(\pi-\pi \delta+w_{2}(y-9 /)\right.
$$

where $P / g \%$ oand $g /$ are target levels for the real interest rate, inflation and output respectively and $w_{1}, w_{2}$ are positive weights. Solving for the reduced form in this case gives:

$$
\begin{aligned}
y & =\frac{\alpha_{1} w_{1}}{1-\alpha_{1} w_{2}} \pi-\frac{\alpha_{2}}{1-\alpha_{1} w_{2}} p+\frac{\alpha_{2}}{1-\alpha_{1} w_{2}} m \\
& +\frac{\alpha_{1}}{1-\alpha_{1} w_{2}} \rho / \frac{\alpha_{1} w_{1}}{1-\alpha_{1} w_{2}} \& \theta-\frac{\alpha_{1} w_{2}}{1-\alpha_{1} w_{2}} \rho / \frac{\alpha_{0}}{1-\alpha_{1} w_{2}}
\end{aligned}
$$

Combining (11) and (4) we can again see that the system has a fixed point when inflation is constant and equal to the money growth rate. 
Note that the denominator $1-\alpha_{1} w_{2}$ for the reduced form equation (11) is unambiguously positive since $\alpha_{1}<0$. The reduced form coefficient for the price level is $b_{2}=-\frac{\alpha_{2}}{1-\alpha_{1} w_{2}}$ and therefore debt-deflation automatically excludes a saddle-path solution. Therefore in this case the condition for the saddle path solution is more restrictive than in the case of the IS-LM model. Next consider the impact of the Taylor rule on the response of output to inflation. The reduced form coefficient in this case is $b_{1}=\frac{\alpha_{1} w_{1}}{1-\alpha_{1} w_{2}}$. In contrast with the IS-LM case this coefficient is unambiguously negative. Therefore by the properties of the dynamic system, if the saddle path condition is not met, then the solution will be either an unstable node or an unstable spiral around the fixed point ${ }^{\mathrm{iii}}$. Moreover the solution will not be unique by virtue of the fact that there is only one predetermined variable.

\section{Conclusions}

In this paper we have demonstrated that the form of the excess demand function is important in determining whether or not the Calvo model generates a unique saddlepath solution. The necessary and sufficient condition for this to occur is that the sign of the price level coefficient in the reduced form output equation should be negative. If there is a positive real balance effect then this condition will be satisfied. However, in the presence of a debt-deflation effect it is less certain. When the excess demand function is the reduced form of the IS and LM equations then a unique saddle path exists even if in the presence of debt-deflation provided this is not sufficiently strong to offset the combination of the liquidity effect of changes in prices on interest rates and the interest rate effect on aggregate spending. When the excess demand function is the reduced form of the IS curve and a Taylor rule then debt-deflation will always result in the failure of the saddle path condition. 
When the saddle path condition fails, the contrast in the dynamic behaviour of the economy under alternative monetary regimes is even more marked. In the case of the IS-LM model, the solution will be stable but not unique due to the fact that the inflation rate is not predetermined. In the case of the IS-Taylor rule model, the solution will be unstable and non-unique. Therefore, although our results have been derived from a very simple macroeconomic model they do indicate that the dynamic properties of the economy may be qualitatively very different when the Taylor rule replaces the LM curve in determining the interest rate. 


\section{References}

Batini, N. (1999) 'Monetary Policy Rules and Inflation Forecasts', Bank of England Quarterly Bulletin, Vol 39, No 1, February, pp 60-67.

Bean, C. (1998) 'The New UK Monetary Arrangement: A View from the Literature', Economic Journal, Vol 108, No 451, November, pp 1795-1809.

Calvo, G.A. (1983) 'Staggered Prices in a Utility-Maximizing Framework’ Journal of Monetary Economics, Vol 12(3), pp 383-98.

Fisher, I (1933) 'The Debt Deflation Theory of Great Depressions', Econometrica, Vol 1, pp 337-357.

Gali, J. and Gertler, M. (1999) 'Inflation Dynamics: A Structural Econometric Analysis’, Journal of Monetary Economics, Vol 44, pp 195-222.

Gali, J., Gertler, M. and Lopez-Salido, J.D. (2001) 'European Inflation Dynamics', European Economic Review, Vol 45, pp 1237-1270.

Goodhart, C. (1999) 'Central Bankers and Uncertainty’, Bank of England Quarterly Bulletin, Vol 39, No 1, February, pp 102-114.

King, M. (1993) 'Debt Deflation: Theory and Evidence', LSE Financial Markets Group Discussion Paper No: 175.

Taylor, J. B. (1993) 'Discretion versus Rules in Practice' Carnegie Rochester Series on Public Policy, Vol 39, pp 195-214.

Svensson, L.E.O. (1997) "Inflation Targeting: Implementing and Monitoring Inflation Targets”, European Economic Review, Vol. 41, No. 6, pp. 1111-1146.

Tobin, J. (1980) Asset Accumulation and Economic Activity, Basil Blackwell: Oxford.

Wolfson, M. (1996) 'Irving Fisher's Debt-Deflation Theory: Its Relevance to Current Conditions’, Cambridge Journal of Economics, Vol 20, pp. 315-333. 


\section{Non-technical Summary}

During the last decade many developed economies have shifted towards a system of monetary arrangements in which an independent Central Bank pursues an inflation target set by government using the short term interest rate as the primary policy instrument. This has been remarkably successful in both bringing down inflation rates and maintaining them at low levels. It is argued that the reason for this success is that the current arrangements are successful in dealing with the combination of dynamic inconsistency and the instability of intermediate targets such as the growth rate of monetary aggregates which plagued earlier systems.

The new monetary system can be summarised neatly by use of the Taylor rule which links the interest rate to a target real rate and deviations of inflation and output from target levels. This effectively replaces the traditional LM curve in the standard short run model of output determination. In doing so it changes the nature of the short run model significantly. In particular, the effect of an increase in inflation is to cause real interest rates to rise and output to fall. This contrasts with the traditional model in which real interest rates fall when inflation increases.

If the interest rate is determined by the Taylor rule then this also has implications for the dynamic behaviour of the economy. When the price level is predetermined but inflation can adjust quickly, then the economy must follow a saddle-path if the solution is to be unique. The condition for this to be the case is that an increase in the price level should have a negative short run effect on aggregate demand and output. In models which allow for debt-deflation it is possible that this condition might not hold. We show that the conditions under which the saddle-path condition is met are less likely to hold when interest rates are set using a Taylor rule.

When the saddle-path condition is not met then the economy behaves very differently in the two cases we consider. In the case where the interest rate is determined by the LM curve, then we show that there will be multiple stable paths all converging on the 
equilibrium solution. In the case where the interest rate is determined by the Taylor rule then there are multiple unstable paths and if the economy is not initially in equilibrium it will diverge. 
${ }^{\mathrm{i}} \mathrm{i}$ The eigenvalues of the coefficient matrix in (7) can be derived as:

$$
\lambda_{1,2}=-\frac{1}{2}\left[\delta^{2} \beta b_{1} \pm \delta \sqrt{\beta^{2} b_{1}^{2} \delta^{2}-4 \beta b_{2}}\right]
$$

$b_{2}<0$ is obviously sufficient for these to be real and of opposite sign. However, when $b_{2}>0$ we have a number of possible dynamic solutions. If $b_{1}<0$ then we have either an unstable node or an unstable spiral centred on the fixed point of the system depending on whether the discriminant $\beta^{2} b_{1}^{2} \delta^{2}-4 \beta b_{2}$ is greater than or less than zero respectively. If $b_{1}>0$ then we have either a stable node or a stable spiral with the same conditions as for the previous case. In either case the solution is clearly not unique since only one of the variables in the system is predetermined.

ii These cases arise when the eigenvalues of the matrix in equation (7) both have negative real part. If in addition they are both real then we have a globally stable node but if they are complex then we have a globally stable spiral. Mathematically it is also possible for the solution to be a stable improper node if $b_{1}>0$ and $\beta^{2} b_{1}^{2} \delta^{2}-4 \beta b_{2}=0$. However, since there is no good economic reason to consider this case we exclude it for simplicity.

iii These cases arise when the eigenvalues of the matrix in equation (7) both have positive real part. If in addition they are both real then we have an unstable node but if they are complex then we have a unstable spiral. It is possible for the solution to be an unstable improper node if $b_{1}<0$ and $\beta^{2} b_{1}^{2} \delta^{2}-4 \beta b_{2}=0$. However, we again neglect this case as being economically uninteresting. 